\title{
EL LIBERALISMO DE JUAN PABLO II*
}

\author{
Richard John Neuhaus
}

Tras reseñar distintos liberalismos contemporáneos y el tenor de las diferencias entre conservadores y "neoconservadores” en el mundo católico estadounidense, el padre Richard John Neuhaus propone en estas páginas rejuvenecer la tradición liberal del "experimento norteamericano” (o democracia liberal), encauzándola a direcciones más promisorias a la luz de la encíclica Centesimus Annus (CA) de Juan Pablo II. Sostiene que no siendo un texto autónomo respecto del magisterio de la Iglesia a lo largo de los siglos, ni historicista, Centesimus Annus entrega una lectura de los tiempos con referencia específica a las experiencias de la historia universal del siglo veinte,

Richard JoHn NeUHAUS. Convertido al catolicismo tras haber sido pastor luterano, y ordenado posteriormente sacerdote, el padre Neuhaus es editor en jefe de First Things: A Journal of Religion and Public Life, una publicación mensual del Institute for Religion and Public Life, con sede en Nueva York, dedicada a la investigación y educación interreligiosa, no partidista, cuyo propósito es promover una filosofía pública religiosamente informada para el ordenamiento de la sociedad. Autor de numerosos artículos y ensayos, entre sus libros están The Naked Public Square y The Catholic Momentum. Su libro más reciente es Catholic Matters: Confusion, Controversy and the Splendor of Truth (2006).

* Este artículo fue adaptado de un documento de trabajo difundido durante una conferencia auspiciada por The Ethics and Public Policy Center, marcando el quinto aniversario de Centesimus Annus.

Traducido del inglés por Martín Bruggendieck para Estudios Públicos. 
y representa una guía de los temas mayores del pontificado de Juan Pablo II, a los que la Iglesia en cada lugar del mundo es invitada a considerar como si estuviesen dirigidos a su propia circunstancia específica. A juicio del autor, antes que una encíclica sobre economía, CA es una encíclica que trata de la sociedad libre, incluida la libertad económica. Entre otros temas presentes en la encíclica, el autor se refiere al individualismo moderno, al estado limitado versus el estado totalitario, los límites de la política, las instituciones de contrapeso y la doctrina de subsidiaridad.

\section{$\mathrm{N}$} mus Annus, hubo entre nosotros quienes no sólo la consideraron una importante instancia del magisterio de la Iglesia, sino que también una vindicación de nuestra forma de entender la doctrina social de la Iglesia. Fue grande la tentación de declarar con aire triunfalista, "Yo se los dije”. Esa tentación no siempre fue resistida como debió serlo. Este hecho contribuyó a generar cierto grado de polarización en torno a la encíclica. Aquellos liberales que siquiera prestaron un poco de atención al documento no quedaron convencidos en absoluto de la defunción del socialismo y exaltaron pasajes que pensaban reforzarían su sueño colectivista. En su mayoría, sin embargo, los liberales prestaron muy poca atención. Tal como ocurrió con los otros importantes documentos magisteriales del pontificado de Juan Pablo II, la aparición de Centesimus Annus no constituyó acontecimiento alguno para la mayor parte de los católicos liberales.

La polarización más marcada se desarrolló entre ciertos conservadores y los así llamados neoconservadores, acusando los primeros a los segundos de secuestrar dicho pontificado y Centesimus Annus en particular, con la finalidad de obtener legitimación magisterial para lo que se llama capitalismo democrático o democracia liberal. A los neoconservadores se $\checkmark$ los describe - y ocasionalmente ellos mismos se describen - como promo¿j tores del "Proyecto Murray", aludiendo al esfuerzo del ya desaparecido * Padre John Courtney Murray para conciliar las enseñanzas de la Iglesia con el experimento democrático norteamericano. Los críticos conservadores - por ejemplo, el Profesor David Schindler, del John Paul II Institute de Washington D.C.- acusan a Murray y a los que piensan como él de abandonar las auténticas enseñanzas de la Iglesia católica en aras de un liberalismo desecado y desecante. 
En su reciente libro, Heart of the World, Center of the Church, Schindler escribe: "Mi argumento, entonces, presentado en nombre de Lubac* y del Papa Juan Pablo II, en cuanto auténticos intérpretes del Concilio Vaticano Segundo, tiene dos implicancias generales: primero, exige que pongamos en entredicho al liberalismo reinante, que insiste en afirmar que (de por sí) no aplica teoría religiosa alguna en su interpretación de la Primera Enmienda, ni de hecho, en su interpretación del constitucionalismo occidental en general. Segundo, exige que busquemos un "momento católico" en los Estados Unidos [diferente del ‘momento católico’ de Richard John Neuhaus], comprendido no como otro momento de Murray sino como un momento propio del Papa Juan Pablo II. Esto significa que debemos poner de manifiesto el engaño que pretende el liberalismo, engaño que precisamente sin argumento alguno le permite colocarse en un lugar privilegiado en la esfera del orden público".

Tanto en su libro como también de forma reiterada en las páginas de la edición en inglés de la revista Communio, de la cual es editor, Schindler ataca lo que califica de "engaño" liberal, dejando entrever que piensa que algunos de nosotros somos cómplices en ese embaucamiento. Confieso que esto me desilusiona un tanto. En mi experiencia, David Schindler es un tipo amigable. Hemos ventilado nuestras diferencias en discusiones tanto privadas como públicas, tras las cuales él termina aceptando que no hay un desacuerdo sustancial entre nosotros. En cuanto a mí, siempre estoy dispuesto para nuestra próxima conversación amistosa, aunque de paso también junto fuerzas para hacer frente a su próximo ataque en público.

Pero estoy convencido de que sí hay una diferencia importante entre nosotros. No se trata, o al menos no se trata en lo principal, de una diferencia en materia de teología católica. La diferencia más bien reside en que el Profesor Schindler y aquellos vinculados con su crítica tienden a interpretar del peor modo posible a la tradición liberal y a la expresión cultural, legal y política que esa tradición tiene en los Estados Unidos. Pienso que al proce-

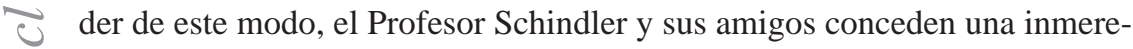
cida victoria a los que interpretan la tradición liberal de un modo que todos deploramos. De acuerdo con John Courtney Murray, yo sugiero que nuestra tarea consiste en pugnar por una interpretación del liberalismo que sea compatible con la plenitud de la verdad católica.

No cabe duda de que el experimento norteamericano se constituyó en la tradición liberal. Como no podemos retroceder al siglo dieciocho y

* Henri de Lubac, teólogo (1896-1991). (N. del T.) 
reconstituirlo sobre otros fundamentos, sólo nos cabe esperar que esos fundamentos sobre los cuales descansa no sean aquellos descritos por Ronald Dworkin, John Rawls, Richard Dorty y David Schindler. Con miras a la comprensión de la tradición liberal como compatible con la verdad católica, no hay guía más valiosa que Centesimus Annus.

Liberalismo, para qué decirlo, es un término extraordinariamente maleable. Allí está el liberalismo económico del laissez-faire, condenado por el Papa León XIII en Rerum Novarum, como también por el Papa Juan Pablo II. En la cultura política de los Estados Unidos, ese liberalismo equivale a libertarianismo, y a pesar de sus numerosos y talentosos apologistas, incluyendo a Charles Murray (ninguna relación con John Courtney), nunca ha reunido un número suficiente de adherentes más allá de lo que Russel Kirk llama algunos “sectarios que pían como avecillas”. En el contexto norteamericano, el libertarianismo sigue siendo en su mayor parte un experimento mental para estudiantes universitarios de segundo año.

El liberalismo tan ferozmente criticado hoy en día, no se limita al libertarianismo. En manos de los críticos, el liberalismo republicano de la virtud y el liberalismo comunitario de la sociedad civil concebido por Tocqueville, apenas son algo mejores que el libertarianismo. David Schindler tiene buenos compañeros en el campo ecuménico para sus ataques tout court contra el liberalismo. Stanley Hauerwas, teólogo metodista que enseña en Duke University, lo ha atacado, martillado, golpeado y demolido con magnífico aplomo en sus innumerables libros. El liberalismo y todas sus variantes y faustos también han recibido recientemente una seria golpiza de parte de Oliver O’Donovan, profesor de la distinguida cátedra de teología de Oxford. A pesar de su sesgo anglicano contra lo que denomina "papalismo”, recomiendo de corazón su libro The Desire of the Nations: Rediscovering the Roots of Political Theology (Cambridge University Press). No se trata sólo de una crítica devastadoramente convincente y de cierta forma de ver el liberalismo, sino que también de un fascinante examen de lo que puede significar la idea de "Cristiandad" en este momento de descontento de nuestra modernidad.

Podemos resumir algunos puntos destacados de las denuncias formuladas por los críticos cristianos del liberalismo y la modernidad (siendo ambos términos más o menos intercambiables). Ya se trate de un embelesado G. K. Chesterton, del casi magistral Alasdair MacIntyre, del cáustico George Grant, del valentón de Stan Hauerwas, del osado O’Donovan o del melancólico David Schindler, la acusación tiende a ser siempre bastante 
similar. A menos que medie algún malentendido, permítaseme decir que coincido de corazón con la descalificación de cierto tipo de liberalismo. La disputa se centra en qué es lo que queremos significar con el término liberalismo.

La primera acusación es que los pensadores cristianos han estado demasiado dispuestos a recortar el mensaje cristiano con la finalidad de acomodar el paradigma cultural reinante del liberalismo. Estoy absolutamente de acuerdo. Pero eso debe verse con mayor exactitud como una acusación contra los pensadores cristianos y no contra el liberalismo. Si vacilamos en declarar públicamente que Jesucristo es el Señor, eso es culpa nuestra. No podemos presentar la excusa de que fue el liberalismo quien nos llevó a ello. Tal vez John Rawls y Richard Rorty o la Corte Suprema de los Estados Unidos, que pretenden hablar en nombre del liberalismo, pueden habernos intimidado, pero la culpa se debe a nuestra timidez.

Hay otros puntos en el contexto de la acusación contra el liberalismo que se expresan de forma variada. Se acusa al liberalismo de ser puramente procesal. Excluyendo la consideración de los fines, el liberalismo plantea tratar únicamente acerca de medios, pero en los hechos oculta sus fines en sus medios. De ahí que la visión que tiene el Padre Murray de la Primera Enmienda como "artículos de paz" constituye —o así reza la acusaciónuna rendición ante el sesgo inherentemente antirreligioso del liberalismo. En breve, la supuesta "neutralidad" del liberalismo es cualquier cosa menos neutral. El liberalismo, se acusa, se erige sobre la ficción de un "contrato social”, cuya premisa descansa exclusivamente en el interés propio. El liberalismo niega o al menos exige un enfoque agnóstico frente a la verdad trascendente o la ley divina, no reconociendo regla superior más allá de la voluntad humana centrada en sí misma. La idea de libertad del liberalismo es libertad respecto de cualquier verdad superior que pueda causar algún efecto sobre la base totalmente voluntarista del orden social.

Estos dogmas liberales, se acusa además, están inextricablemente igados a la dinámica del capitalismo El dogma liberal y la dinámica del mercado constituyen los fundamentos, que se refuerzan mutuamente, y la finalidad de un ordenamiento social que se halla entera y totalmente al servicio de las opciones individualistas de un yo soberano, autónomo y libre de trabas. El liberalismo apuesta al consumismo y el consumismo es algo que lo consume todo. El resultado final es algo que determinados críticos llaman "totalitarismo liberal". 
Se trata de una acusación notable, respaldada por pruebas también notables. Personalmente he escrito detalladamente en contra de todas las distorsiones mencionadas, como también han escrito otros que tienen una actitud favorable hacia la democracia liberal o, como prefieren decir aún otros, el capitalismo democrático. Pero éste es precisamente el punto: puede uno argumentar que la acusación es una denuncia contra las distorsiones del liberalismo. De ser el caso, estamos luchando por el alma misma de la tradición liberal.

Tal vez éste sea el momento para algunas palabras personales. En la década de 1960 yo era una persona cercana a las izquierdas. No militaba en aquella izquierda contracultural de drogadicciones varias y hedonismo generalizado, pero me atraía una izquierda como aquella del movimiento por los derechos civiles que encabezaba el Dr. Martin Luther King Jr. En la segunda mitad de los sesenta, la situación comenzó a cambiar con el advenimiento del debate en torno a lo que se llamaba ley de aborto "liberalizada”. En 1967 yo escribía sobre los “dos liberalismos”, uno semejante al antiguo movimiento pro derechos civiles, que incluiría también a las personas en riesgo social y cuyo impulso nacía del deseo de una justicia trascendente; el otro era excluyente, y no reconocía una ley más elevada que la sola voluntad individual. Para entonces, mi argumento rezaba que los liberales, al abrazar la causa del aborto, hacían abandono del liberalismo inicial, aquel que ha sustentado todo aquello que resulta esperanzador en el experimento norteamericano.

Y éste es mi argumento hasta el día de hoy. Pienso que es crucialmente importante que ese argumento prevalezca en los años venideros. No hay vuelta atrás para reconstituir el orden estadounidense sobre otro fundamento que no sea el de la tradición liberal. Se ha abierto un enorme abismo entre la tradición liberal y aquello que hoy se llama liberalismo. Es ésta la razón por la cual a parte de nosotros se nos llama conservadores. Aquel conservadurismo que es auténtica y constructivamente conservadurismo norteamericano, es una posición conservadora por la causa de repensar y revitalizar la tradición liberal.

Y es con miras a este fin que Centesimus Annus presta, como ya dije, una guía inestimable. Este documento papal a menudo se describe como una encíclica sobre economía, aunque yo sugiero que tal descripción es engañosa. Cierto, trata cuestiones económicas en considerable detalle. Una de las razones de esta situación es que Centesimus Annus conmemora y desarrolla el argumento de Rerum Novarum, que mostraba gran y justificada preocupación por los problemas del trabajador y la amenaza de lucha de 
clases en una temprana fase del capitalismo. Otro motivo para centrarse en la economía es que el Papa hace referencia a la situación que siguió al suicidio del imperio soviético, asistido por Occidente, un imperio que se había justificado a sí mismo sobre la base de una ideología falsa que reducía el fenómeno humano a la dimensión económica. Para explicar por qué esa ideología era falsa y a la vez poder indicar un camino hacia un futuro más promisorio, era necesario que la encíclica prestara estricta atención a la economía.

Más exacto, sin embargo, sería decir que Centesimus Annus trata de la sociedad libre, incluyendo la libertad económica. La discusión de Rerum Novarum, es decir, de la correcta comprensión de la propiedad y el mercado y de las circunstancias que siguieron después de los trascendentales acontecimientos de 1989, culmina en los capítulos V, "Estado y Cultura”, y VI, "La persona es el camino de la Iglesia”. Cuando consideramos a la encíclica en relación con el liberalismo norteamericano, cabe tomar diversas precauciones. Centesimus Annus no es un texto autónomo. Debe comprenderse en el marco del vasto corpus de este enérgico pontificado magisterial y aún más allá, en el contexto de la moderna doctrina social de la Iglesia, que data de Rerum Novarum. Más aún, debe comprenderse como una continuación del ministerio magistral de la Iglesia a lo largo de los siglos. Además, siempre debemos guardar en mente que el Papa escribió para la Iglesia universal y dirigiéndose a ella.

Sin embargo, aún manteniendo ésta y otras precauciones en mente, uno no puede hacer más que sorprenderse de hasta qué punto Centesimus Annus es una lectura de los "signos de los tiempos", con referencia específica a las experiencias de la historia universal de este siglo. La encíclica no es historicista, en el sentido estrecho de ese término, pero está firme y decididamente ubicada en un momento histórico. Y si bien no es un texto autónomo, a través de este solo texto pueden seguirse los temas mayores de este pontificado magisterial. Si bien está dedicada a esa Iglesia y está escrita para ella, la Iglesia de cada lugar del mundo es invitada y obligada a leer la encíclica tal como si estuviese dirigida a su propia circunstancia específica.

Más aún, estoy confiado en que nosotros, como norteamericanos, no cometemos un error cuando pensamos que el experimento norteamericano marca una presencia importante en Centesimus Annus. Después de todo, las democracias occidentales y aquella de los Estados Unidos muy en particular, son las alternativas históricas a mano para un socialismo que fracasó tan miserablemente. Pienso que es verdad decir que en este pontificado y 
por primera vez, la enseñanza magistral sobre la modernidad, la democracia y la libertad humana tienen una mayor referencia a la Revolución de 1776 que a la Revolución Francesa de 1789. Por tanto, no es ni chauvinista ni provinciano leer Centesimus Annus con particular referencia al experimento norteamericano. Por el contrario, es el curso de la fidelidad, hecho imperativo por el deber de asimilar el magisterio a nuestras propias circunstancias, y también por la poderosa conciencia del experimento estadounidense que tiene el autor de Centesimus Annus.

No hay una crítica más común a la tradición liberal que decir que ésta se supone construida sobre la base de un individualismo "descomedido". Centesimus Annus habla del “individuo” e incluso del "sujeto autónomo” (13), aun cuando casi siempre refiere a la "persona”. Citando su encíclica anterior, Redemptor Hominis, Juan Pablo II escribe que "esa persona humana es la ruta primaria que la Iglesia debe tomar para el cumplimiento de su misión ... la ruta trazada por Cristo mismo, el camino que conduce invariablemente a través del misterio de la encarnación y de la redención”. Enseguida agrega la notable afirmación, “éste y tan sólo éste es el principio que inspira a la doctrina social de la Iglesia” (53).

Éste y tan sólo éste. Escribe el Papa: "La Iglesia ha desarrollado esta doctrina gradualmente y de modo sistemático”, especialmente en el siglo pasado. De modo muy gradual, podríamos agregar sin desmerecerla. En su encíclica posterior, Veritatis Splendor, Juan Pablo II paga tributo cabal a la modernidad y al desarrollo de su comprensión tanto de la dignidad del individuo como de la libertad individual. El individualismo es uno de los logros señeros de la modernidad o, si se prefiere, de la tradición liberal. No deberíamos tampoco negar que este logro se alcanzó bajo una frecuente tensión e incluso conflictos con la Iglesia católica. Una de las razones importantes de dicho conflicto fue, desde luego, que la causa de la libertad fuera percibida como marchando bajo los estandartes radicalmente anticlericales y anticristianos de 1789. Constituye un logro señero del pontificado de Juan Pablo II haber replantado tan claramente la idea del individuo y de la libertad en el rico suelo de la verdad cristiana, del que había sido arrancada en el curso de un tortuoso y conflictivo desarrollo. Sólo profundamente enraizada en la verdad del ser humano es que florecerá en el futuro la flor de la libertad.

Constituye un error enfrentar, como algunos lo hacen, al individualismo moderno con una comprensión católica más orgánica de la comunidad. Más bien deberíamos establecer un contacto benévolo con ese logro moderno que es la idea de individuo, arraigándola más firme y plenamente 
en la comprensión de la persona, destinada por la eternidad para la comunión con Dios. El riesgo de rechazar al individualismo es que la alternativa del mundo real ya no sea una comprensión católica de communio, sino que una recaída en los colectivismos que constituyen el gran enemigo de la libertad a la que todos nos sentimos llamados. Como nos recuerda Centesimus Annus, "No estamos tratando aquí con la humanidad 'abstracta', sino que con la persona real, 'concreta e histórica'”. El problema con la distorsión contemporánea del individuo como un ente soberano, autónomo y libre de ataduras, no es que se esté equivocado en cuanto a la imponente dignidad de ese individuo, sino que se aísla a ese ser justamente de la fuente de esa dignidad. La causa primera de ese error, nos dice Centesimus Annus, es el ateísmo (13).

"Es respondiendo al llamado de Dios contenido en el ser de las cosas que el hombre se vuelve consciente de su dignidad trascendental. Será cada individuo quien dé esa respuesta, que constituirá la cumbre de su humanidad, y ningún mecanismo social o sujeto colectivo podrá sustituirlo en ello" (13). El gran error del determinismo colectivista, así como de la licencia individualista, es que su comprensión de la libertad humana está separada de la obediencia a la verdad. (17) Si bien la cultura es un fenómeno de la comunidad, está al servicio de la respuesta de la persona ante la verdad trascendental. En uno de los pasajes más sugerentes de Centesimus Annus, Juan Pablo II escribe: "En el corazón de cada cultura yace la actitud que toma una persona frente al más grande de los misterios: el misterio de Dios. Las diferentes culturas son básicamente diferentes modos de encarar la pregunta por el significado de la existencia personal” (24).

Nos vemos ahora de regreso a la memorable proposición sobre el florecimiento de la persona humana. "Éste y sólo éste es el principio que inspira a la doctrina social de la Iglesia". No se trata de un individualismo en el sentido peyorativo, pero es coincidente con el alcance moderno de la idea de individuo. Es coincidente con las ideas constituyentes del experimento norteamericano, en que el Estado está al servicio de la libertad, y ésta es a su vez comprendida como aquello que los Padres Fundadores llamaron "libertad ordenada”, libertad ordenada a la verdad. Y hay, como enseña la Declaración de la Independencia de los Estados Unidos, "verdades evidentes en sí mismas", que arraigan dicha libertad y la encauzan hacia los fines trascendentes de "la Naturaleza y al Dios de la Naturaleza".

Las referencias teístas de la Declaración norteamericana no son, como insisten algunos comentaristas, simples apartes para satisfacción de las muchedumbres, sino que parte integral del argumento moral del docu- 
mento - y la Declaración es, por sobre todo, un argumento moral. Más aún, tales referencias deben ser comprendidas en el contexto de las innumerables declaraciones de cada uno de los Padres Fundadores, en el sentido de que el orden constitucional está construido sobre verdades morales afincadas en la religión. El experimento norteamericano está constituido por una síntesis del pensamiento de Locke con aquel de la corriente puritana, que en décadas recientes ha sido expurgada para calzar con los prejuicios seculares de las elites académicas norteamericanas. Es imperativo que cuestionemos dicha versión expurgada de los fundamentos con que se ha embaucado a ya varias generaciones de estudiantes, desde la educación básica hasta la universitaria, con el fin de entender nuestra historia norteamericana tal como es.

Habrá quienes protesten aduciendo que esto es mera "religión civil”. Pero si pensamos que es algo “mero" sostener un ordenamiento público que reconozca la fuente trascendente y el fin de la existencia humana, habremos entendido mal lo que nos dice Centesimus Annus. Desde luego que un reconocimiento formal ofrece solamente una teología muy ligera y atenuada, pero crea la condición en cuyo marco la Iglesia puede proponer una relación rica y adecuada de la historia humana. Pero ése, se objeta, es justamente el problema: en una sociedad liberal, la Iglesia sólo puede proponer su verdad, colocando al Evangelio en el mercado como un bien de consumo más entre tantos.

Es ésta una objeción que se escucha con frecuencia y debemos preguntarnos qué es lo que entiende la gente por ella. ¿Acaso se sugiere que la Iglesia debería obligar a las personas a viva fuerza a obedecer a la verdad? En la encíclica sobre evangelización, Redemptoris Missio, el Papa dice: “La Iglesia no impone nada, ella sólo propone”. Ella no impondría, aun si pudiese. La fe auténtica es por necesidad un acto de libertad. Si no entendemos esto, habrá que temer que no entendemos lo que Juan Pablo II llama el principio que por sí solo inspira a la doctrina social de la Iglesia. La Iglesia debe proponer —sin descanso, vigorosamente, convincentemente, gozosamente. Si nosotros, que somos la Iglesia, no lo hacemos, la falta no es del liberalismo, sino que nuestra. Si bien la Iglesia provee un terreno seguro para el liberalismo, el liberalismo no es el contenido del mensaje de la Iglesia. Simplemente es la condición para que la Iglesia invite a personas libres a vivir en comunidad con Cristo y con su Cuerpo Místico, comunión que es infinitamente más profunda, rica y plena que el ordenamiento social liberal, o, para este caso, que cualquier ordenamiento social falto del correcto ordenamiento que tienen todas las cosas en el Reino de Dios. 
Pocas cosas son más importantes para la sociedad libre que la idea del Estado acotado o limitado. Sin embargo, no importa cuánto pueden haberlo negado en décadas recientes los tribunales y los intelectuales seculares, el orden norteamericano es imposible de explicar al margen del reconocimiento de una soberanía más elevada que el Estado. Como en "una nación bajo Dios”, frase que significa una nación a ser juzgada. Los cristianos lo entienden y lo declaran públicamente en una simple proposición: “Jesucristo, nuestro Señor”. No hay necesidad de que el Estado declare que Jesucristo es el Señor. Tampoco es deseable que el Estado declare que Jesucristo es el Señor, al menos no en la actual circunstancia norteamericana, ni en cualquier reconfiguración previsible de esa circunstancia. La función del Estado limitado es respetar la soberanía política de un pueblo que reconoce una soberanía superior a la propia. Como dice la encíclica: "Por medio del sacrificio de Cristo en la cruz, se ha alcanzado de una vez para siempre la victoria del Reino de Dios” (25). Esa victoria denota la más alta soberanía mediante la cual se circunscribe al Estado, y la proclamación de esa victoria es el más importante aporte político de la Iglesia. En una sociedad democrática que ha sido efectivamente evangelizada, los ciudadanos no solicitan al Estado confesar la supremacía del reinado de Cristo. Su única demanda es que el Estado respete el hecho de que una mayoría ciudadana reconoce el soberano reino de Cristo. Nosotros no profesamos un Estado confesional, sino que una sociedad confesional, recordando siempre que el Estado es el servidor de la sociedad, que es anterior al Estado.

La Iglesia también realiza un aporte político inestimable cuando insiste en los límites de la política. El gran peligro, dice Centesimus Annus, es que "la política se convierta en 'religión secular', operando bajo la ilusión de crear el paraíso en la tierra. Pero ninguna sociedad política ... debe jamás confundirse con el Reino de Dios ... Al presumir ser capaz de anticipar el juicio aquí y ahora, las personas se colocan en el lugar de Dios y contravienen la paciencia de Dios". El poder de la gracia "se propaga” a través del orden político, especialmente cuando el laicado toma la iniciativa en el ejercicio de la responsabilidad pública cristiana, pero no se puede pretender que la política terrenal establezca el debido orden final que desean nuestros corazones (25).

Así como en el ordenamiento liberal las ambiciones del Estado son frenadas tanto por la reafirmación democrática de una soberanía superior como por los límites de la política misma, esas ambiciones son frenadas por diversas "soberanías" al interior de la sociedad misma. Como hiciera León 
XIII, el Papa Juan Pablo II declara que "el individuo, la familia y la sociedad son anteriores al Estado”. El Estado existe para servir y proteger a los individuos y a las instituciones que tienen prioridad (11). Las personas humanas y lo que ya he descrito en otra parte como las instituciones mediadoras de la sociedad, “disfrutan de sus propias esferas de autonomía y soberanía”, como reza Centesimus Annus (45). Esas esferas de soberanía son menores que el Estado pero no están por debajo del Estado.

La asombrosa modernidad del argumento de la encíclica se hace también evidente en su comprensión del Estado. A diferencia de formulaciones anteriores, el Estado no es situado al interior de una jerarquía de autoridades, descendiendo desde el poder de Dios hasta el gobierno del señor de la tierra. El argumento de Centesimus Annus es profundamente democrático. Cristo es el soberano por sobre todo y esa soberanía es reconocida por todos aquellos que reconocen la soberanía de Cristo. El Estado ilimitado, ya sea que esté basado en el marxismo ateo o en la ingeniería política del racionalismo ilustrado, aspira al control totalitario. "De modo que hay una negación de la suprema toma de conciencia de lo que es la verdadera grandeza del hombre, de su trascendencia frente a las realidades terrenales, de la contradicción en su corazón entre el deseo de plenitud de aquello que es bueno y su propia incapacidad de obtenerlo y, por sobre todo, de la necesidad de salvación que deriva de esta situación” (13). El Estado limitado se mantiene acotado por la afirmación democrática del deseo trascendente del corazón humano.

En relación con este tema, Juan Pablo II insufla una nueva vitalidad a la doctrina de la subsidiaridad mediante el uso de la más sugerente de las frases: "la subjetividad de la sociedad”. Prosigue el Papa: “La naturaleza social del hombre ... se realiza en diversos grupos intermediarios, comenzando por la familia e incluyendo a grupos económicos, sociales, políticos y culturales que se originan en la naturaleza humana misma y disfrutan de su propia autonomía, siempre con miras al bien común” (13). En la sociedad libre, el Estado es una institución, es un actor más entre otros. Es un actor indispensable por el servicio que presta a los demás actores, pero está sujeto a la subjetividad de la sociedad, y la subjetividad de la sociedad consiste en personas libres y en personas libres viviendo en comunidad bajo la obediencia a Dios y en solidaridad entre sí. Pienso que tanto en Centesimus Annus como en otros escritos emanados del pontificado de Juan Pablo II hay una refrescante y urgente teoría de la democracia, que aguarda un desarrollo sistemático de parte de la próxima generación. 
Si se busca un Estado que permanezca acotado, debe reinar un cultivado escepticismo. "Para esa finalidad es preferible que cada poder sea equilibrado por otros poderes y por otras esferas de responsabilidad que lo mantengan dentro de límites apropiados" (44). El escepticismo frente al poder del Estado no significa, sin embargo, escepticismo frente a los propósitos que el Estado ha de servir. El caso es más bien todo lo contrario. Sólo cuando dichos propósitos se afirman de modo claro y carente de ambigüedades, podrá el Estado ser tenido como responsable. La sección 45 de Centesimus Annus cuestiona clara y directamente el punto en que el liberalismo ha distorsionado de forma más severa el significado de la democracia en la tradición liberal. He aquí el párrafo crucial:

La verdadera democracia es posible sólo en un Estado regido por la ley y sobre la base de un concepto correcto de la persona humana. Se requiere la presencia de las condiciones necesarias para el avance tanto del individuo, a través de la educación y su formación en los ideales verdaderos, como de la "subjetividad" de la sociedad a través de la creación de estructuras de participación y responsabilidad compartidas. [Y acto seguido viene el pasaje vital]. En nuestros días existe la tendencia a proclamar que el agnosticismo y el relativismo escéptico constituyen la filosofía y actitud básica que corresponderían a las formas democráticas de la vida política. Aquellos convencidos de que conocen la verdad y que adhieren firmemente a ella son considerados poco confiables desde un punto de vista democrático, dado que no aceptan que la verdad es determinada por la mayoría, o que está sujeta a variaciones de acuerdo con las diversas tendencias políticas. En este sentido debe observarse que si no hay una verdad ulterior que guíe y dirija a la actividad política, las ideas y convicciones pueden ser fácilmente manipuladas por razones de poder. Como demuestra la historia, una democracia sin valores puede fácilmente convertirse en un totalitarismo apenas disimulado.

La importancia de este párrafo y su pertinencia para la situación en los Estados Unidos no pueden subestimarse. La dogmática insistencia en el agnosticismo en el discurso público y en la toma de decisiones, ha generado lo que yo llamo "la plaza pública desnuda". Personas que, como los Fundadores, tienen ciertas verdades por evidentes en sí mismas, son actualmente "consideradas de poca confianza desde el punto de vista democrático”. En lo que constituye una usurpación de poder, que en verdad amenaza 
con un "totalitarismo apenas disfrazado", las cortes de justicia se han aventurado a declarar que la separación del Estado y la Iglesia significa separar de la vida pública tanto la religión como la moral fundada, lo que significa separar de la política las convicciones más profundas de la gente, lo que a su vez significa el fin de la democracia y, de hecho, el fin de la política. Gracias a Dios no hemos llegado todavía a eso. Sin embargo, es ésa la dirección en que nosotros, los norteamericanos, nos hemos desplazado estas últimas décadas, $\mathrm{y}$ es el verdadero y actual peligro que precisa que aquellos de nosotros a los que llaman conservadores, nos alcemos para defender la tradición liberal.

En la contienda por el alma del liberalismo debemos benévolamente prestar atención a algunos de nuestros conciudadanos que honestamente piensan que cualquier mención de una verdad trascendente plantea la amenaza de una teocracia. Juan Pablo II reconoce cuán difundido está este malentendido y por tal motivo procede a agregar inmediatamente el siguiente pasaje:

Tampoco cierra la Iglesia sus ojos ante el peligro del fanatismo o del fundamentalismo entre aquellos que en nombre de una ideología que presume ser científica o religiosa propagan su derecho a imponer a otros su propio concepto de lo que es la verdad y lo bueno. La verdad cristiana no es de ese tipo. Dado que no es una ideología, la fe cristiana no presume encarcelar realidades sociopolíticas cambiantes en un esquema rígido, y reconoce que la vida humana se realiza en la historia bajo condiciones diversas e imperfectas. Más aún, al reafirmar constantemente la dignidad trascendente de la persona, el método la Iglesia siempre será el de respeto a la libertad.

Digamos de modo inocente que éste no siempre ha parecido el método de la Iglesia. No deberíamos dejar que otros destaquen este punto. En Tertio Millennio Adveniente (El tercer milenio que adviene), así como en otras numerosas ocasiones, el Papa ha solicitado con franqueza a los cristianos que reconozcan cómo, individual y corporativamente, han fallado en respetar la dignidad y la libertad de otros. Pero ese reconocimiento debe sumarse a otras dos proposiciones. Primero: cuando en nombre de la democracia se excluye de la arena pública a la verdad trascendente, el resultado es un "totalitarismo manifiesto o velado". Segundo: el totalitarismo democrático, que no reconoce verdad más elevada que el gobierno de la mayoría, genera una circunstancia traicioneramente peligrosa para las minorías. 
Podríamos proseguir examinando otros temas de Centesimus Annus que podrían correlacionarse con la tradición liberal, rejuveneciendo dicha tradición y encauzándola hacia direcciones más promisorias. Ahí está, por ejemplo, la relación entre libertad y virtud, tanto personal como pública, que debe suscitar un esfuerzo intensificado hacia la evangelización y reevangelización de la sociedad. Lo que está en juego en este esfuerzo es muy importante, como insiste con tanta urgencia Juan Pablo II en la dramática representación que hace del conflicto entre "la cultura de la vida" y "la cultura de la muerte" en la encíclica Evangelium Vitae. Pero éste y otros asuntos deben quedar para otra oportunidad. En efecto, como ya indiqué, será labor de varias generaciones desplegar y diseminar de modo sistemático el extraordinario magisterio de su pontificado.

Comencé escribiendo algunos comentarios sobre Centesimus Annus y lo que algunos llaman "el proyecto Murray". Nadie debiera intentar usurpar la autoridad de documentos magistrales con el fin de avanzar argumentos proselitistas particulares intracatólicos. Ante el magisterio de la Iglesia todos somos aprendices. Nuestro propósito debe ser sentire cum ecclesia, debe ser pensar con la Iglesia. En cuanto a mí, sé que he aprendido de Centesimus Annus y sé que me ha cambiado y confío que esto seguirá sucediendo. En caso alguno la encíclica debe ser interpretada como una afirmación sin reservas del experimento norteamericano. De muchas maneras, Centesimus Annus es una crítica temible de lo que ha llegado a ser ese experimento bajo la influencia de los diversos liberalismos contemporáneos. Sin embargo, sí pienso que Centesimus Annus es conciliable con la tradición liberal norteamericana, como pienso que marca una continuidad crítica con la gran obra de John Courtney Murray. Pienso que ése es el caso y espero que sea el caso, pues no podemos darnos el lujo de imaginar la reconstitución de este ordenamiento social y político sobre fundamentos que no sean la tradición liberal.

Con toda la simpatía que podríamos abrigar respecto de determinados críticos del liberalismo, hacemos bien en recordar que todos los ordenamientos temporales al margen del Reino de Dios son profundamente insatisfactorios. Cuando hacemos una evaluación de las depredaciones y estragos propios de nuestras circunstancias sociales, políticas y religiosas, resulta tentador buscar algo o alguien a quien echar la culpa. Es fácil decir, "el liberalismo nos llevó a hacerlo". Pero el liberalismo es libertad y lo que hacemos con él cae en nuestra cuenta. Para los cristianos de Norteamérica y en particular para los católicos, no hay nada que haya sido mal hecho que 
no hubiera podido hacerse de otro modo. En medio de las depredaciones y estragos de un experimento norteamericano que alguna vez llegó a exaltar el espíritu humano y que puede volver a hacerlo, Centesimus Annus nos invita a recuperar y reconstruir la tradición liberal. 